\title{
Kaleidoscope of Swiss Cartography
}

\author{
Stefan Räber ${ }^{\mathrm{a},} *$, Lorenz Hurni ${ }^{\text {a }}$ \\ ${ }^{a}$ Institute of Cartography and Geoinformation,ETH Zurich, Stefan Räber, raebers@ethz.ch, Lorenz Hurni, lhurni@ethz.ch \\ * Corresponding author
}

Keywords: Historical Maps, Swiss Cartography, International Map Year, SSC, $50^{\text {th }}$ anniversary

\begin{abstract}
:
Motivation

In 2015/2016 the Zentralbibliothek Zürich (ZB, Zurich Central Library) and the Swiss Society of Cartography (SSC) presented a map blog to mark the 2015/16 International Map Year. In this weekly blog, cartographer and map librarian Markus Oehrli described and commented on 70 known and less-known Swiss map documents. In 2017, the map history journal Cartographica Helvetica published 58 of these 70 map documents in a special issue. In 2019, SSC will translate the blog into English, which will be published in its publication series to mark the $50^{\text {th }}$ anniversary of the society.
\end{abstract}

During the 2015/16 International Map Year, which was initiated and proclaimed by the ICA, national cartographic societies were encouraged to organise various kinds of public activities and events as part of this worldwide celebration of maps. The SSC coordinated and organised more than 20 of these events within Switzerland. The "Karte der Woche" (Map of the week) blog, which was offered an in-depth and sometimes surprising look at Swiss cartography, was received with much enthusiasm by the general public and experts alike. During the 70-week map year (between August 2015 and December 2016), the blog provided a comprehensive profile of Swiss map-making on the website http://cartography.ch.

\section{Map year blog: 70 maps in 70 weeks}

The documents presented in the blog cover both current and historical productions evenly. The oldest map dates from before the year 900 and the most recent from 2016. The exhibits include traditional maps for which Swiss cartography is widely known and world-renowned, i.e. topographical maps, hiking maps, city maps, road maps, bird's-eye views, statistical maps, and school maps. A relief model, a horizontal panorama, a pictorial map, an infographic and numerous thematic maps relating to folklore, navigation, archaeology, sport, etc. are also to be found. Furthermore, geo-media is also represented and includes such as maps produced by means of geographical information systems and web map mashups. In contrast, techniques that have almost been forgotten today, such as typometry and map printing on silk, are also presented. A very special historic piece is the $16^{\text {th }}$ century globe by Abraham Gessner which can also be used as a drinking cup. There are even maps of subterranean and lunar worlds or maps of imaginary places. Some of the authors or producers of the presented documents are well-known cartographic publishers and federal institutions, but some are little known individuals working away on their own. Besides trained cartographers, the blog also features work by a priest, a spy and an artist.

For the purpose of this blog, only maps created by Swiss authors or published by a Swiss publishing house were selected. Another selection criterion was the fair balance among the different regions in Switzerland. All parts of the country and almost all cantons feature at least once. In order to document the global network of Swiss cartography, about a third of the presented documents also show areas outside of the country's borders.

The blog offers plenty of background information and is spiced with a pinch of humour, without ever losing sight of the central theme - Swiss cartography. The individual blog texts were researched and written by Markus Oehrli who is a long-standing SSC member. The pictures have been published with the consent of the copyright holders. Where possible, a link within the blog refers to a high-resolution image or to an interactive map application on the Internet. The first blog entry was published on 4 September 2015 and each further blog was released every Friday until 30 December 2016.

\section{Special issue - Kaleidoskop der Schweizer Kartografie (Kaleidoscope of Swiss Cartography) in German}

In 2017, Cartographica Helvetica, the leading German-language journal for map history, devoted a 64-page special issue to the map blog. Under the title "Kaleidoskop der Schweizer Kartografie" ("Kaleidoscope of Swiss Cartography"), a selection of 58 documents from the blog were printed in the issue in a new, innovative way, both in terms of graphics and content. In addition, this edition of Cartographica Helvetica was published in digitized form on 
the Swiss journal repository e-periodica.ch. It is free to access and offers features such as full text search, an advanced search using various filters, the ability to browse page by page, the enlargement of pages up to about $600 \%$, download possibility for all pages and all articles as PDF documents. The repository navigation is trilingual, in German, English and French.

\section{English edition part of SSC's 50 ${ }^{\text {th }}$ anniversary celebrations in 2019}

In order to meet the great demand for the widely acclaimed map blog and the "Kaleidoskop der Schweizer Kartografie" special issue - which sold very well - SSC decided to publish the blog also in English to help commemorate its $50^{\text {th }}$ anniversary in 2019. This will make the content accessible to an even wider public. With this contribution we propose to announce and publish the English version during a presentation to an international audience of experts at ICC 2019 in Tokyo. We will give insight how the 70 artefacts were chosen according to the scientific, geographic and thematic selection criteria. The composition of the accompanying texts is based upon the thorough scientific research especially carried out for this project. We hope that this approach may serve as a model for similar projects showing the richness of excellent cartographic artefacts all over the world!

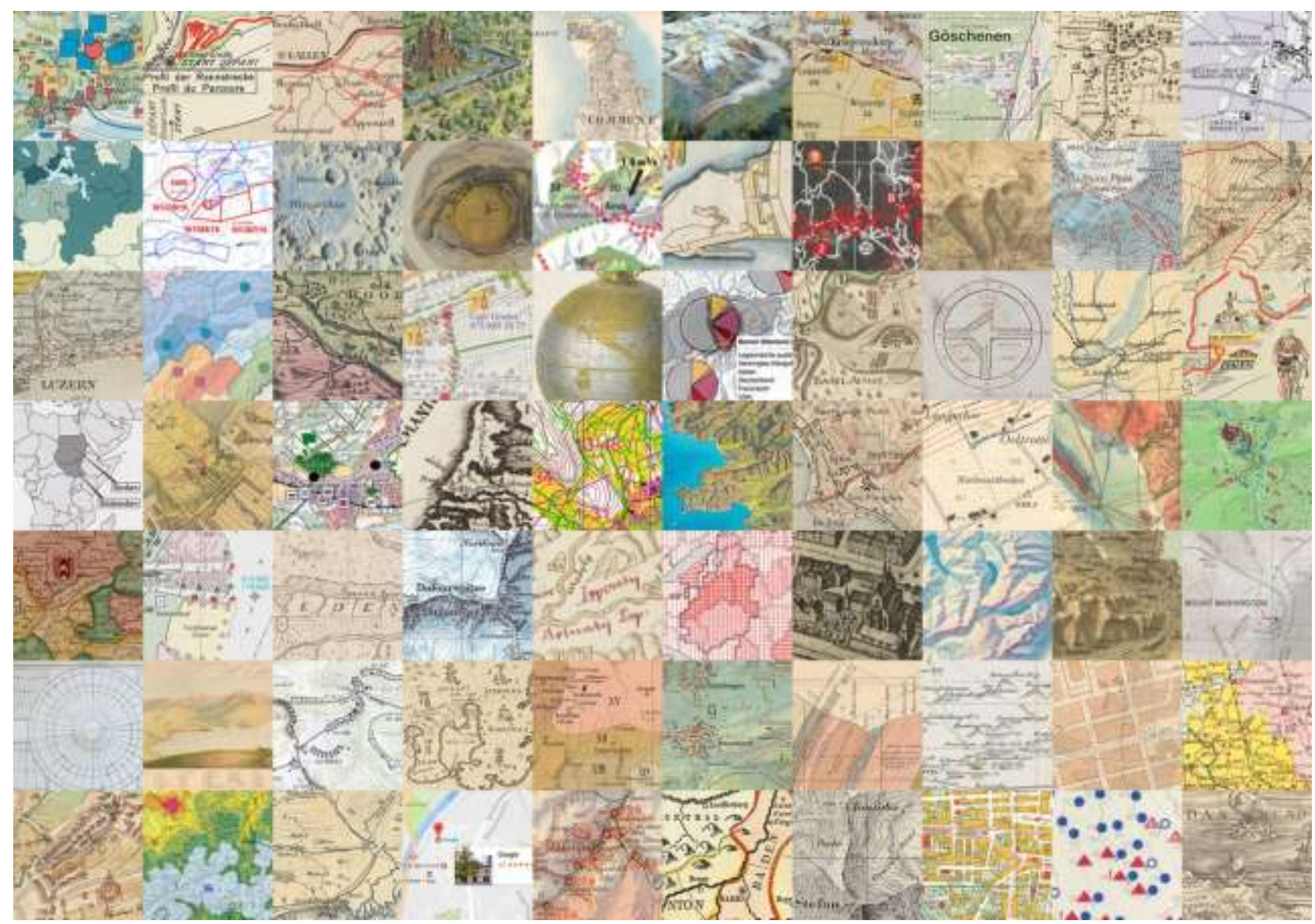

Figure 1. Collage of the 70 maps presented in the map blog.

\section{References}

Oehrli, M. (2017). Kaleidoskop der Schweizer Kartografie. Cartographica Helvetica, vol. 55, 64 pp. Murten.

Oehrli, M., Räber, S. (2016). Karte der Woche (Map of the week), Schweizerische Gesellschaft für Kartografie SGK (Swiss Society of Cartography SSC) [accessed April 4, 2019]. https://cartography.ch/imy/list/ 